results of his own observations during the time he lived with the natives as one of themselves. He found them to be undoubted cannibals, and predicts their early extinction.

One of the most original and scientific papers in the Section was that of Dr. Guppy on the south coast of West Java. The author dealt with a part of Java which has not been much described. It is one of the least familiar portions of this large island, a circumstance due partly to its paucity of anchorages and to the difficulty in landing; partly to its having been allowed to become in some places a kind of menagerie ; and partly, also, to the fact that it lies remote from the chief seats of government. Now that the Netherlands Indian Government are rapidly carrying out their systematic survey of the Preanger Residency, it will not be long before the south coast of West Java will be much better known than it is at present; and the recent extension of the central railway to Garoet and Tjirajap will do much to effect this end. The author's tracks over West Java would make a chequered pattern on a map; but he has thought it best not to refer to localities already well known-localities which are now yearly visited by hundreds of visitors. Taking the central railway as his base, he performed nearly all the distance on foot, walking about 560 miles in all. In the paper he endeavoured to give a general idea of this south coast alone. The huge volcanic cones were landmarks to him, and nothing more; they had been well described by Junker and others, so he resisted the temptation of climbing them, and reserved his main efforts for the examination of the little-described and remote south consts of the Preanger and Bantam Residencies. The object he had in view was to ascertain what physical evidence there was for the belief that the west end of Java was originally united with Sumatra. In this paper the author showed that all the evidence on the Java side of the Sunda Sirait points to the opposite con clusion. Zoological evidence cannot be held sufficient to establish the previous connection between two islands without the physica evidence of such a change. The problem, as usually stated, seems to begin at the wrong end of the matter. Given the present distribution of plants and animals, it is then attempted to explain the previous arrangement of the land, and this is done too often without appealing to the physical evidence at all. In tracing geographical changes in the past, it would seem more reasonable to adopt an opposite method; but in the great majority of cases affecting the distribution of animals, it would be wiser in the first place to assume the status quo, and fall back when that fails on the physical evidence of the presumed changes.

As was rightly pointed out by Mr. H. J. Mackinder, Dr. Guppy's apparent contempt of the argument from zoological distribution is to be deplored. Hitherto it has been regarded, and rightly so, by the ablest biologists and geographers, as one of the surest and most valuable keys to past geographical conditions; and it will require much more powerful arguments than Dr. Guppy was able to adduce in his paper to cast it aside.

In a paper on recent explorations in Peru and Bolivia, Mr. $\mathrm{H}$ Guillaume described the efforts which have been made by Peruvian and Bolivian explorers and traders to open up the rivers and the dense forest country lying between them. Colonel Labre since 1872 has been endeavouring to open communication from the Purus to the Beni. He explored the River Itury and its affluents several times, as to the character and navigability of which he has contributed much new information. Padre Nicolas Armentia explored the Madre de Dios in 1885 , and resided for some time in the country of the Araonas Indians. From its mouth for 280 miles the river receives no important tributary the Padre believes it has a navigable course of 400 miles for steamers. Mr. Guillaume described in detail the gold-bearing region at the source of the Madre de Dios. He then referred to the expiorations of Senor Carlos Fry on the Ucayli and its tributary, the Urubamba.

Mr. Theodore Bent's paper, on his recent visit to the Bahrein Islands in the Persian Gulf, was a contribution of some originality on the present condition, the antiquity, the inhabitants, and past history of this interesting group. Dr. Nansen's paper on Greenland was identical with that given to the Geographical Society, and already reported in NATURE.

The Report presented to this Section by Mr. Joseph Thomsor, on the geography and geology of the Atlas Mountains, can hardly be said to contain anything that has not already appeared in his narrative, except the lists of plants and of Coleoptera.

On the whole, it will be seen that the Geographical Section has not a very brilliant account to render.

\section{THE MECHANICAL PAPERS AT THE BRITISH ASSOCIATION.}

MONG the papers read in Section G, after the President had delivered his address, was one hy Mr. Alex. C. Humphreys, on water-gas in the United States. Water-gas is produced by the decomposition of steam by incandescent carbon. The two ways of effecting the decomposition, the intermittent and continuous, were described. In the first a cupola furnace is used : a blast of air raises the fuel to the necessary temperature; when this is effected the air is cut off and steam turned on, the blowing in of air and steam occurring intermittently. In the continuous process, steam is passed uninterruptedly through retorts containing carbon, which are heated externally, or steam and air are forced in continuously through a cupola furnace; but the latter proces: has the disadvantage of the resultant gases containing nitrogen. Water-gas has no light-giving properties so that it has to be carburized for illuminating purposes, or employed to raise some solid substance to a white heat. The different processes in vogue were described, and their theory explained. In conclusion the author gave expression to the belief that the day of gas, fuelgas, was rapidly approaching ; that even the great rival of gas, the electric light, may yet be dependent on it for the cheapest means of producing the electric current. Then will the gas engineer and the electrical engineer, shoulder to shoulder, be striving to correct the present wasteful strains on Nature's storehouses.

Precautions to be adopted when the electric light is supplied by means of transformers, by Mr. Killingworth Hedges. In a paper the author read at the Southport meeting of the British Association, he urged the necessity of regulations, and the adoption of proper safety appliances, in connection with electric lighting. In this paper he refers to the danger incurred when currents of high tension are converted into pressures suitable for incandescent lamps by means of transformers. The precaution necessary in such cases is either to earth the secondary circuit-which, however, has certain disadvantages-or to connect one or both of the leads to a safety appliance, which would automatically divert any excess current to earth, and at the same time shut off the supply in that portion of the faulty circuit by the fusion of the lead wire or mica-foils in the main cut-outs. Numerous experiments have been made with a vacuum protector, designed by the author, to ascertain the distance which an alternating current of high E.M.F. will leap across the two electrodes, which were fixed in the opposite ends of a glass tube from which the air had been partially excluded. The results differ from those observed by De la Rue with continuous currents ; the following phenomenon was noticed-that the arc, after starting between the two points, almost invariably extended itself to a bow-shape and ran back to the base of one or both of the platinum electrodes, one of which nearly always fused, leaving the other intact.

Electric launches on the Thames, by Prof. G. Forbes, F.R.S. Launches are chiefly wanted in the summer; to prevent injuries to banks the speeds should not be high, so that a comparatively small supply of accumulators is required. The author experimented with the Delta, 33 feet long, 6 feet beam, fitted with forty-four cells, weighing 2520 pounds. She is steered by a wheel in front within reach of three handles required to work her. The first is to put the current on or off; the second for half or full speed, and the third for going ahead or astern. The first is mechanically locked with the others, so that they cannot be moved without first cutting off the current. Fusible cut-outs are inserted to prevent injury to the motor if the propeller becomes jammed. The batteries are under the seats on each side of the boat, thus leaving clear space for passengers, of which she could carry twenty. The pull at full speed gives I 44 horsepower, or 1074 watts, including electrical losses, slip, and all friction. The average pressure at the motor terminals during the run was 78 volts, and the average current 23 amperes, which gives 1794 watts expended. This gives a total efficiency of 60 per cent. The author suggested that negotiations should be opened with the Thames Conservancy to establish charging stations, as there was likely to be a great demand in the future for electric launches.

Series electrical traction (Northfleet Tramways), by Mr. Edward Manville, M.Inst.C.E. The economical distribution of electrical power over long distances involves the use of a current of high potential, and by running the motors in series the advantages of high potential are secured. The main features of a series electrical tramway are a dynamo producing a current 
of constant quantity, a closed metallic circuit of which travelling motors at all times form a part without ever being short-circuited, or having the current supply cut off from them, and the regulation of the power developed by the motor and absorbed by it without interrupting the continuity of the circuit. An insulated cable connected to one terminal of the generator traverses the whole length of the line, and is interrupted at distances of 20 feet, the divided ends being connected with the opposite faces of a "spring jack," which is at the same time the automatic switch and contact point. The current collector, which is the same length as and carried by the car, is constructed so as to pass between the faces of the "spring jack," and conduct the current to the motor without at any time short-circuiting it or interrupting the main circuit. In series running, there is little danger of damage to the motor by careless driving, or reversing while running ; in descending a gradient there is positive advantage in checking the speed of the car by altering the field connections, so that the armature tends to revolve in the opposite direction to that in which the car is travelling; the power that would otherwise be lost in braking is thus added to that produced by the generator.

Telephonic communication between London and Paris, by Mr. W. H. Preece, F.K.S. The difficulty of such a communication was not the distance, 275 miles, between the two towns, as in the United States speech is maintained between New York and Boston, $35^{\circ}$ miles apart; but the insertion of underground wires at each end, and of a cable in the middle, places difficulties in the way that have to be surmounted. The author has experimented on the cables between Dover and Calais and others, and finds the conditions to be fulfilled simple. The circuit must be metallic, the material copper, and the product of the resistance of the line and its capacity must not exceed 7500 for very good, 5000 for excellent, and 2500 for perfect speech. A circuit approaching as nearly as possible one between London and Paris was made on an artificial cable, and found to comply with the requirements.

On the purification of sewage and water contaminated with organic matter by electrolysis, by Mr. W. Webster. The paper was divided into four sections, of which the fourth referred to the use of the electric current. The fact that water and the salts contained therein are easily decomposed if the current is of sufficient intensity is the explanation of the whole system. The changes taking place in sewage when electrolyzed depend chiefly on the splitting up into their constituent parts of sodium, magnesium, and other chlorides, nascent chlorine and oxygen being set free at the positive and the bases at the negative pole.

The strength of alloys at different temperatures by Prof. W. C. Unwin, F.R.S. In 1877 , the Admiralty made some experiments as to the effect of variation of temperature on the tenacity of copper, Muntz metal, and phosphor bronze, and found that up to $500^{\circ} \mathrm{F}$. the tenacity diminished proportionately with increase of temperature ; in the case of gun metal, on the other hand, the tenacity diminished regularly up to $300^{\circ}$ to $350^{\circ}$, but beyond this temperature there was a sudden reduction in the strength, which was found to be as low as half that at ordinary atmospheric temperature, whilst at $500^{\circ}$ it became nil: the gun metal tested consisted of alloys of copper, tin, and zinc combined in different proportions. The author determined to make a series of experiments, the results of which he brought before the Association. The various alloys used, which are tabulated below, were heated in an oil bath, the temperatures employed, being all below that of the boiling of mercury, were read by means of a mercury thermometer. The results were plotted on a diagram, and given in tables, and show that the decrease of tenacity follows a regular law in each case ; the temperature was given in degrees Fahrenheit, and the tenacity in tons on the square inch.

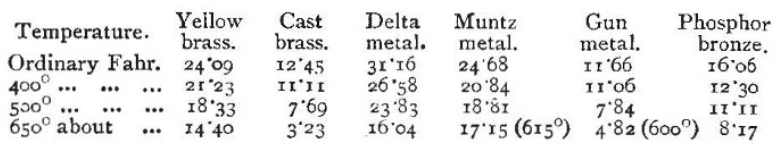

The influence of variation of temperature on the ductility of the same alloys was also experimented on, and was found to vary with the different alloys; with brass and gun metal there was little elongation before fracture ; with Muntz metal it was considerable. In these cases the ultimate elongation diminished with increase of temperature, but in the case of Delta metal it increased. These experiments are of a very important character, and were carried out by the author on account of the very high pressures, and therefore temperatures, at which modern steamengines are worked.

Central station heating and power supply, by $\mathrm{Mr}$. W. W. Phipson. The system consists in the constant circulation of water at high temperature and pressure (viz. $400^{\circ} \mathrm{F}$. and 250 pounds per square inch) from boilers at the supply station, through supply mains covered with non-conducting material, and back to the boilers by means of return mains, the circulation being maintained by pumps. Service boxes to supply the houses are fixed under the footpaths, which are connected to the mains by an inch pipe. From these boxes the house supply is taken by means of copper pipes. A vessel, called a converter, is fixed inside the house, whose use is to permit the water to resolve itself into steam, the pressure of which is controlled by means of a reducing-valve fixed on the copper pipe, before it enters the converter. From this converter the house services are taken. If a supply of both heat and power is required, double or compound converters are used with two reducing-valves, the power being taken from one and the heat from the other.

A curve ranger, by Mr. Alex. P. Trotter. The instrument is an application of the twenty-first proposition of the third book of Euclid, viz. the angles in the same segment of a circle are equal. A half-silvered mirror, such as is used in sextants, is mounted on an axis at one end of a bar, the other being provided with a sight. The motion of the mirror on its axis allows its inclination to the sight to be adjusted. To set out a curve, a pole is set up at each extremity, and the mirror is suitably adjusted. When the poles are seen, the one direct through the unsilvered part and the other by reflection in the silvered part of the mirror in apparent coincidence, and in the middle of the field as shown by the vertical line engraved on the mirror, the instrument is then at the point on the curve required. The mirror being clamped in position, the observer walks in the direction of the curve, and at suitable intervals places himself so that the poles at the extremities of the curve are seen in apparent coincidence.

On the application of the transporting power of water to the deepening and improvement of rivers, by $\mathrm{Mr}$. W. H. Wheeler, M.Inst.C.E. The object of the paper is to show that the transporting power of water may be applied to the proposed purpose, and that under favourable conditions this can be accomplished by breaking up shoals, or the natural bed of a river, by mechanical agency and by mixing the material with the water, and allowing it to be carried away to the sea or estuary in suspension. The author has designed an improved apparatus, which, whilst disintegrating the shoal, mixes its material with the water, allowing it to be effectively transported by the ebb current clear of the channel to be improved.

\section{THE ANTHROPOLOGICAL PAPERS AT THE BRITISH ASSOCIATION:}

THE work of the Section commenced on Thursday, September I.2, by Mr. Francis Galton, F.R.S., reading a paper on the advisability of assigning marks for bodily efficiency in the examinations of candidates for the public services. In the recent report of H.M. Civil Service Commissioners, they state that, a scheme of competition for physical qualifications having been brought before the notice of the War Office, it was not accepted, on the ground that the authorities were " completely satisfied with the physique of the young men who came to them through our examinations." The marks, as at present, of the candidates whose places lie near the dividing line between success and failure, run pretty evenly; therefore it is contended that the State would obtain better servants if such moderate marks were allowed for physical qualifications as to insure the selection of the most efficient in body from among those who are nearly on a par intellectually.

Mr. Galton also read a paper on the principle and methods of assigning marks for bodily efficiency. Two separate considerations are involved in the just determination of a scale of marks, which are usually mixed up in unknown proportions. (I) Absolute performance-on the principle that if the daily output of one man is greater than that of another, he should be more highly paid, or marked, in that proportion. (2) Relative rankon the principle that superiority, however small, insures success 